\title{
Formação profissional em odontologia: percepção discente da interação curricular
}

\author{
Mariana Gabriel*, Elisa Emi Tanaka**
}

\author{
* Estudante do curso de mestrado em Clínica Odontológica da \\ Universidade Estadual de Londrina \\ ** Coordenadora do Curso de Odontologia da Universidade Estadual \\ de Londrina/UEL
}

\section{RESUMO}

Há algum tempo se faz necessária à mudança nos currículos de odontologia do Brasil, com um modelo de ensino voltado ao mercado de trabalho na qual o estudante tenha a excelência técnica associada a um pensamento crítico. Em 2005 ocorreu a mudança do currículo tradicional para o transdisciplinar na Universidade Estadual de Londrina, orientados pelas Diretrizes Curriculares Nacionais de 2002 o qual almeja que o estudante consiga articular conceitos e necessidades específicas de cada caso. Com o objetivo de avaliar qual a percepção discente da mudança curricular ocorrida foi aplicado um questionário com questões extraídas do Exame Nacional de Desempenho dos Estudantes - ENADE aos estudantes do quinto ano do Curso de Odontologia da primeira e segunda turma do currículo transdisciplinar e a última turma do currículo tradicional $(\mathrm{n}=148)$. Os resultados foram analisados e quantificados pelo software estatístico SPSS versão 15.0 e Excel 2007 que possibilitou cruzar os dados das três turmas e fazer uma análise comparativa e nesse momento de renovação as variações entre as turmas foram pertinentes para apontar algumas mudanças ocorridas, como por exemplo, o avanço na atuação em conjunto com outras áreas profissionais, maior compreensão de processos, tomada de decisão e resolução de problemas no âmbito de sua área de atuação. Esses avanços não se devem apenas a mudança metodológica, mas a uma transformação na cultura pedagógica da instituição que ainda está em fase de construção por meio de ações que visam orientar adequações necessárias para um efetivo currículo integrado.

\section{DESCRITORES}

Educação em Odontologia. Avaliação Educacio- nal. Estudantes de Odontologia.

E star em formação implica um investimento pessoal, um trabalho livre e criativo sobre os percursos e os projetos próprios, com vista à construção de uma identidade, que é também uma identidade profissional. ${ }^{8}$

O modelo de ensino superior odontológico brasileiro é predominantemente centrado na formação técnica, ${ }^{9}$ com dificuldades para encontrar e universalizar soluções adequadas à realidade do país.

Sendo assim a educação superior deve assumir a formação de competências para atuar na solução dos problemas da Saúde Bucal do País. ${ }^{2}$ O objetivo é que o aluno adquira a excelência técnica associada a um pensamento crítico para saber o quê fazer, quando fazer, como fazer, onde fazer, por que e para quem fazer o que significa estabelecer um diagnóstico ampliado da situação. Preparando o profissional para a solução dos problemas e ser ativo na construção do seu conhecimento, conduzindo, de maneira contínua, em direção a uma formação integral e mais humana.

Para a proposição do novo modelo de profissional a ser formado deve ser analisado o mercado de trabalho, com suas tendências e indicações, e associar aos dados epidemiológicos atualizados, visando um profissional mais completo em ações não apenas reproduzindo técnicas consagradas da profissão, mas assimilando as reais necessidades para desviar o foco da doença e passar para a saúde do individuo.

Vários marcos legais históricos do Brasil ${ }^{1}$ proporcionaram transformações nas últimas décadas mediante institucionalização do Sistema Único de Saúde (SUS) o que direcionou a formação em Odontologia para a agregação de novos conhecimentos e tecnolo- 
gias até chegar ao modelo de ensino hoje observado.

Por outro lado, somente estas medidas não garantem por si só que a Universidade se integre ao seu meio, identifique-se com seus problemas e influa para mudar a realidade social. É necessário tratar, especificamente, da questão da mudança do conteúdo e das práticas. Estas não são decorrência automática de qualquer mudança metodológica, mas demandam uma transformação na cultura pedagógica da instituição. ${ }^{2}$

Em 2005 houve a mudança do currículo na Universidade Estadual de Londrina na qual temos módulos integradores das áreas de conhecimento. Não há hierarquia entre essas áreas. O trabalho baseia-se no planejamento coletivo dos programas e em evidências científicas educacionais, que dão suporte a essa integração. ${ }^{10}$

Essas ações foram avaliadas e propostas coletivamente pelos docentes de várias áreas e após sua implantação inicial concorreu e foi contemplado com recursos do Programa Nacional de Reorientação da Formação Profissional em Saúde (Pró-Saúde) $)^{5}$ que tem por objetivo subsidiar os cursos que se propuseram a realizar mudanças curriculares, incentivando a integração ensino-serviço, visando à reorientação da formação profissional assegurando uma abordagem integral do processo saúde-doença com ênfase na atenção básica.

O objetivo desse trabalho é conhecer a percepção que o acadêmico de odontologia da UEL faz dessa mudança, ou seja, se o estudante consegue identificar esses novos conceitos, nos quais destacam a importância do aluno no seu processo de aprendizagem, a responsabilidade do profissional da área de saúde com as necessidades sociais, a atuação interdisciplinar do cirurgião dentista e se as mudanças na orientação teórica, nos cenários de prática e nas orientações pedagógicas estão surtindo efeito em seu produto final.

\section{METODOLOGIA}

O método utilizado para esse trabalho baseou-se em um estudo quantitativo e comparativo desenvol- vido mediante pesquisa e um formulário aplicado aos estudantes de odontologia da primeira (turma $64-$ $\mathrm{n}=50$ ) e segunda turma (turma $65-\mathrm{n}=44$ ) do currículo transdisciplinar e a última turma (turma 63 $\mathrm{n}=54$ ) do currículo tradicional da Universidade Estadual de Londrina. A participação na pesquisa foi voluntária, com obtenção do termo de Consentimento Livre e Esclarecido de cada sujeito.

As questões foram extraídas do questionário do ENADE, Exame Nacional de Desempenho dos Estudantes, ${ }^{3}$ composto por dez questões de múltiplas escolhas com cinco alternativas, as quais abordam a percepção que o estudante faz referente à contribuição do curso na sua formação profissional e como a instituição formadora influenciou para o desenvolvimento das competências necessárias a sua formação.

Os resultados foram analisados e quantificados pelo software estatístico SPSS versão 15.0 e Excel 2007 que possibilitou cruzar os dados das três turmas e fazer uma análise comparativa.

\section{RESULTADOS E DISCUSSÃO}

Após realizar a tabulação dos resultados foi possível observar as seguintes respostas das turmas avaliadas:

Para a maioria dos estudantes a principal contribuição do curso foi à aquisição de formação profissional (Tabela 1). Tendo em vista que um dos principais problemas com os quais os recém-formados se deparam é a dificuldade de ingressar no mercado de trabalho de suas profissões, ${ }^{11}$ é fundamental que a Universidade norteie esse processo fornecendo subsídios para orientar o estudante em suas decisões por meio de indicadores e vivências práticas da profissão.

No momento atual passamos por uma desmistificação do serviço público, que com a priorização das Políticas Públicas de Saúde Bucal, proporcionaram diversas possibilidades de trabalho, com vínculo público exclusivo, vínculos públicos parciais e os que não possuem vínculo empregatício com o serviço público, mas são credenciados pelo Sistema Único de Saúde - SUS. ${ }^{7}$

Ter a percepção das possibilidades de atuação pro-

Tabela 1 - Média das respostas das três turmas.

\begin{tabular}{|c|c|c|c|c|c|c|c|c|c|c|}
\hline & 1 & 2 & 3 & 4 & 5 & 6 & 7 & 8 & 9 & 10 \\
\hline Turma 63 & $\begin{array}{c}C \\
85,18 \%\end{array}$ & $\begin{array}{c}\text { A } \\
42,59 \%\end{array}$ & $\begin{array}{c}\text { B } \\
42,59 \%\end{array}$ & $\begin{array}{c}\text { B } \\
44,44 \%\end{array}$ & $\begin{array}{c}\text { B } \\
46,29 \%\end{array}$ & $\begin{array}{c}\text { B } \\
35,18 \%\end{array}$ & $\begin{array}{c}\text { B } \\
40,74 \%\end{array}$ & $\begin{array}{c}\text { B } \\
40,74 \%\end{array}$ & $\begin{array}{c}\text { C e D } \\
33,33 \%\end{array}$ & $\begin{array}{c}\text { B } \\
44,44 \%\end{array}$ \\
\hline Turma 64 & $\begin{array}{c}C \\
90.00 \%\end{array}$ & $\begin{array}{c}\text { A } \\
30,00 \%\end{array}$ & $\begin{array}{c}\text { B } \\
44,00 \%\end{array}$ & $\begin{array}{c}\text { B } \\
56,00 \%\end{array}$ & $\begin{array}{c}\text { B } \\
52,00 \%\end{array}$ & $\begin{array}{c}\text { B } \\
52,00 \%\end{array}$ & $\begin{array}{c}\text { B } \\
40,00 \%\end{array}$ & $\begin{array}{c}C \\
40,00 \%\end{array}$ & $\begin{array}{c}C \\
64,00 \%\end{array}$ & $\begin{array}{c}C \\
56,00 \%\end{array}$ \\
\hline Turma 65 & $\begin{array}{c}C \\
79,54 \%\end{array}$ & $\begin{array}{c}\text { B } \\
50,00 \%\end{array}$ & $\begin{array}{c}\text { B } \\
54,54 \%\end{array}$ & $\begin{array}{c}\text { B } \\
38,63 \%\end{array}$ & $\begin{array}{c}\text { B } \\
61,36 \%\end{array}$ & $\begin{array}{c}\text { B } \\
54,54 \%\end{array}$ & $\begin{array}{c}\text { B } \\
38,63 \%\end{array}$ & $\begin{array}{c}C \\
38,63 \%\end{array}$ & $\begin{array}{c}C \\
47,72 \%\end{array}$ & $\begin{array}{c}\text { C } \\
47,72 \%\end{array}$ \\
\hline
\end{tabular}


fissional pode contribuir positivamente na inserção no mercado de trabalho do recém-formado mesmo que sua opção seja pautada na atuação privada.

Quanto à atuação ética, com responsabilidade social, para a construção de uma sociedade includente e solidária as turmas 63 e 64 acreditam que o Curso contribuiu amplamente, já à turma 65 a maioria acredita ter contribuído parcialmente. Se relacionarmos os inúmeros problemas de Saúde Bucal que o Brasil vive no momento atual e o papel da Universidade como instrumento de inclusão proporcionando ações coletivas de grande peso social, observamos que embora exista um avanço ainda estamos em déficit para um modelo social homogêneo. Essa postura mais crítica por parte do estudante aponta o aumento do nível de compreensão com a realidade da saúde pública, certamente devido à aproximação com diferentes eixos de atuação do profissional da saúde que o estudante está sendo apresentado durante a sua formação, evidencia também a transformação na postura por meio de profissionais mais comprometidos com a sociedade.

Em relação à organização, expressão, comunicação do pensamento, raciocínio lógico e análise crítica as três turmas na sua maioria acreditam que o curso contribuiu parcialmente, de acordo com uma das mudanças de paradigmas que ocorreu na organização curricular deve-se buscar estabelecer uma nova relação entre professor-aluno, em que o docente seja capaz de incluir os estudantes como componentes ativos no processo ensino-aprendizagem motivados e cientes da sua importância, buscando caminhos alternativos em que o professor é facilitador e mediador desse processo. ${ }^{6}$

Porém para que estas mudanças se concretizem é necessário transformações da rotina docente e por este motivo encontram-se muitas resistências por parte dos professores, o que o causa no estudante certa insegurança em assumir a responsabilidade de sua formação.

Quanto à compreensão de processos, tomada de decisão e resolução de problemas no âmbito de sua área de atuação a maioria também respondeu que o curso contribuiu parcialmente, no entanto observamos maior porcentagem positiva, nessa alternativa, da turma 65 , mostrando que a integração dos módulos está cada vez mais favorecendo a resolubilidade clinica desejada capacitando o estudante a atuar com rigor técnico e cientifico associado pensamento crítico buscando a saúde. A autoconfiança está diretamente relacionada ao desenvolvimento da competência de tomada de decisão que deve ser baseada em raciocínio lógico para construção de diagnóstico ampliado. Saber diagnosticar favorece a tomada de decisão, pois permite uma abordagem completa da situação fazendo com que os procedimentos sejam suportados e realizados de maneira mais segura e correta.

Atuação em equipes multi, pluri e interdisciplinares e observação, interpretação e análise de dados e informação, os estudantes da turma 63 responderam em menor quantidade que foi contemplada em relação à turma 64 e 65, sendo essa proporção já esperada, pois as turmas do currículo transdisciplinar foram contempladas com o programa de educação tutorial em saúde PET-Saúde, uma estratégia do Pró-Saúde que proporciona a aproximação e a integração ensino-serviço como uma forma de aprendizagem fazendo com que o estudante conheça a organização, planejamento e gestão dos serviços de saúde do município e região, além de atuar diretamente com a população em equipes multidisciplinares ampliando seus conhecimentos e articulando com a promoção de saúde por meio de indicadores epidemiológicos de diversas áreas colhidos dentro das Unidades Básicas de Saúde que os estudantes atuam.

Essa aproximação com a epidemiologia associada à vivência das Unidades e territórios de abrangência também favoreceu a observação, interpretação, análise de dados e informação, as três turmas acreditam terem sido contempladas.

$\mathrm{Na}$ questão da utilização de procedimentos de metodologia científica e de conhecimentos tecnológicos para a prática da profissão a maioria se sente parcialmente contemplados. A mudança curricular orienta que seja elaborado um trabalho de conclusão de Curso sob orientação docente, ${ }^{4}$ objetivando estimular o raciocínio crítico aplicado e global desde o primeiro ano.

A Universidade busca através de projetos de ensino, extensão e iniciação cientifica recursos para proporcionar aos estudantes melhor contato com inovações tecnológicas no exercício da profissão, no entanto a demanda de recursos algumas vezes é insuficiente.

Em relação à assimilação crítica de novos conceitos as respostas foram menos favoráveis das turmas 64 e 65, talvez devido à dificuldade de compreender que mais do que conhecer técnicas e desenvolver habilidades sofisticadas a graduação deve fornecer subsídios para se conseguir desviar o foco da doença e passar para a saúde do individuo e para isso se faz necessário saber articular conceitos das ciências básicas dentro da prática clínica. 


\section{CONSIDERAÇÕES FINAIS}

Tendo em vista a fase de transição curricular que o curso de odontologia da Universidade Estadual de Londrina vivência a avaliação discente é satisfatória. Os estudantes em sua maioria se sentem contemplados ou parcialmente contemplados aos questionamentos propostos durante a avaliação em relação a sua formação.

Mudanças significativas na visão discente puderam ser observadas, um senso mais crítico em relação à formação nas turmas do currículo transdisciplinar em comparação ao tradicional, apontando a evolução na autonomia adquirida durante a formação.

Avanços na prática da profissão demonstram que a Universidade está conseguindo avançar com a mudança proposta, embora existam dificuldades, os estudantes estão mais próximos da realidade do país e mais competentes nas suas atividades.

Esses avanços não se devem apenas a mudança metodológica, mas a uma transformação na cultura pedagógica da instituição que ainda está em fase de construçãopormeiodeaçõesquevisamorientaradequações necessárias para um efetivo currículo integrado e para isso as avaliações devem continuar acontecendo.

\section{ABSTRACT}

\section{Professional dentistry training: students' perception} of curricular interaction

A change in Brazil's Dentistry curriculum is long overdue. Its teaching model should be geared toward the job market, in which the student can associate technical expertise with critical thinking. In 2005, there was a change from the traditional Flexnerian to the transdisciplinary curriculum at the State University of Londrina, guided by the National Curriculum Guidelines of 2002, the aim of which was to enable students to interconnect the concepts and specific needs of each case. In order to ascertain students' perceptions of curriculum changes, a survey with questions taken from the National Survey of Student Performance (ENADE) was applied to fifth year Dentistry students $(n=148)$ from the first and second class of the transdisciplinary curriculum and from the last class of the traditional curriculum. The results were analyzed and quantified by SPSS version 15.0 and Excel 2007 statistical software that allowed cross referencing the data from the three classes and making a comparative analysis. At a time of renewal such as this, the variations between classes have made it possible to identify some changes, such as the progress made in joint operations with different professional areas, greater understanding of processes, professional decision making and problem solving. This progress is not just a methodological change, but a transformation in the teaching culture of the institution, still being constructed through actions designed to guide necessary adjustments for an effective integrated curriculum.

\section{DESCRIPTORS}

Education, Dental. Educational Measurement. Students, Dental. .

\section{REFERÊNCIAS BIBLIOGRÁFICAS}

1. Andrade SM, Soares DA, Cordoni Junior L, organizadores. Bases da Saúde Coletiva. Londrina: Eduel, 2001.

2. Araujo ME Palavras e silêncios na educação superior em odontologia. Ciência \& Saúde Coletiva. 2006;11(1):179-82.

3. Brasil. Ministério da Educação. Instituto Nacional de Estudos e Pesquisas Educacionais Anísio Teixeira. Questionário sócioeconômico do ENADE - 2006. [homepage na Internet]. Acesso em: 18/01/2011.Disponível em: http://download.inep.gov.br/ download//enade/2006/QS.pdf

4. BRASIL. Ministério da Educação. Conselho Nacional de Educação. Câmara de Educação Superior. Resolução CNE- CES 3, de 19/02/2002. Institui as Diretrizes Curriculares Nacionais do curso de Graduação em Odontologia. Diário Oficial da República Federativa do Brasil, Brasília, 04 de março de 2002. Seção 1, p. 10.

5. Brasil. Ministério da Saúde. Pró-Saúde-Programa Nacional de Reorientação da Formação Profissional em Saúde [homepage na Internet]. Acesso em: 25/02/2011. Disponível em: www. prosaude.org

6. Lazzarin HC, Nakama L, Cordoni Junior L. O papel do professor na percepção dos alunos de Odontologia. Saúde \& Sociedade. 2007;16(1):90-101.

7. Morita MC, Haddad AE, Araújo ME. Perfil atual e tendências do cirurgião dentista brasileiro. Maringá: Dental Press; 2010.

8. Nóvoa A. Os professores e sua formação. Lisboa: Dom Quixote; 1997.

9. Paula LM, Bezerra ACB. A estrutura curricular dos cursos de Odontologia no Brasil. Revista da ABENO. 2003;3(1):7-14.

10. Peralta CHG. Projetos pedagógicos e reformas curriculares: texto para reflexão. Rio Grande: Universidade Federal do Rio Grande; 2000.

11. Teixeira MAP, Gomes WB. Estou me formando...e agora? reflexões e perspectivas de jovens formandos universitários. Revista Brasileira de Orientação Profissional. 2004;5(1):47-62. 